\title{
Synthesis of Vorinostat and Cholesterol Conjugate to Enhance the Cancer Cell Uptake Selectivity
}

\author{
Nethrie D. Idippily \\ Cleveland State University \\ Chunfang Gan \\ Guangxi Teachers Education University \\ Paul Orefice \\ Cleveland State University \\ Jane Peterson \\ Cleveland State University \\ Bin Su Ph.D. \\ Cleveland State University, B.SU@csuohio.edu
}

Follow this and additional works at: https://engagedscholarship.csuohio.edu/scichem_facpub

Part of the Medicinal-Pharmaceutical Chemistry Commons

How does access to this work benefit you? Let us know!

\section{Publisher's Statement}

Link to publisher version: http://dx.doi.org/10.1016/j.bmcl.2017.01.025

\section{Recommended Citation}

Idippily, Nethrie D.; Gan, Chunfang; Orefice, Paul; Peterson, Jane; and Su, Bin Ph.D., "Synthesis of Vorinostat and Cholesterol Conjugate to Enhance the Cancer Cell Uptake Selectivity" (2017). Chemistry Faculty Publications. 528.

https://engagedscholarship.csuohio.edu/scichem_facpub/528

This Article is brought to you for free and open access by the Chemistry Department at EngagedScholarship@CSU. It has been accepted for inclusion in Chemistry Faculty Publications by an authorized administrator of EngagedScholarship@CSU. For more information, please contact library.es@csuohio.edu. 


\title{
Synthesis of Vorinostat and cholesterol conjugate to enhance the cancer cell uptake selectivity
}

\author{
Nethrie D. Idippily, Chunfang Gan, Paul Orefice, Jane Peterson, Bin Su
}

\author{
A R T I C L E I N F O \\ Article history: \\ Received 2 December 2016 \\ Accepted 9 January 2017 \\ Available online 10 January 2017 \\ Keywords: \\ LDL-receptor \\ Cancer \\ SAHA \\ Cholesterol
}

Rapidly growing cancer cells need cholesterol to generate new cell membranes. It has been demonstrated that cancer cells show an increased uptake of low-density lipoprotein (LDL) ${ }^{1,2}$ Blood cholesterol level in cancer patients has been found to be lower than in normal subjects. ${ }^{1,3} \mathrm{LDL}$ is the major cholesterol carrier in plasma, and its uptake is mediated by the LDL-receptor (LDL-R), a glycoprotein overexpressed on the surface of cancer cells. Apolipoprotein B on the LDL particles can be recognized by LDL receptor and medicates the endocytosis of LDL into cytosol. ${ }^{4}$ Cholesterol is released by the hydrolysis of cholesterol esters in the LDL. Based on this process, it seems that cholesterol can be used as a delivery agent to enhance the selective penetration of anti-cancer drugs into cancer cell cytosol via LDL-receptor. It has been reported that cholesterol non-covalent conjugated with chemo agent platinum enhanced the cancer cell uptake., ${ }^{5,6}$ However, the stability of the non-covalent conjugate makes the application of this novel strategy difficult.

Herein, we report a cholesterol and chemo agent conjugate via covalent bond, and the covalent bond is designed to be hydrolyzed by the liposomal digestive enzymes. Histone deacetylase (HDAC) inhibitor Vorinostat (SuberAniloHydroxamic Acid, SAHA) was used as the parental compound to design the cholesterol conjugate (Fig. 1)

HDAC inhibitors are a class of promising multi-functional anticancer agents. $^{7-9}$ These agents are able to regulate the gene transcription via chromatin remodeling, eventually modulating a variety of cellular functions including proliferation, differentiation, and apoptosis. The multiple-functional characteristics contribute to their strong anti-cancer potency across a wide range of hematologic malignancies. ${ }^{7}$ Vorinostat, the first HDAC inhibitor approved by FDA in 2005, has been well used in clinic for cancer treatment. ${ }^{10}$ To conjugate cholesterol into SAHA, an amino group was introduced on the $4^{\prime}$ position of the aromatic ring of the compound in order to conveniently form the designed amide bond. It has been reported that 4-amino SAHA showed anti-proliferative activity comparable to SAHA. ${ }^{11}$ The synthesis of the conjugate is illustrated in Scheme 1. Our hypothesis is that the carbamate of the conjugate could be hydrolyzed by the liposomal lipase, which is a process similar to the hydrolysis of cholesteryl esters. The decarboxylation will follow after the hydrolysis and a carbon dioxide molecule will be released, which will generate 4-amino SAHA and cholesterol.

It has been reported that the carbamate group could be hydrolyzed by liver or plasma digestive enzymes. ${ }^{12}$ After the synthesis of the conjugate, it is necessary to determine if the carbamate group between cholesterol and 4-amino-SAHA could be hydrolyzed by the enzymes in the cytosol. As illustrated in Fig. 2, 4-amino-SAHA 
<smiles>O=C(O)CCCCCCC(=O)Nc1ccccc1</smiles>

\section{Suberanilohydroxamic acid SAHA}<smiles>CC(C)CCC[C@H](C)[C@H]1CCC2C3CC=C4C[C@@H](OC(=O)Nc5ccc(NC(=O)CCCCCCC(=O)NO)cc5)CC[C@]4(C)[C@H]3CC[C@]21C</smiles>

Fig. 1. Cholesterol conjugated with SAHA.

in cell lysate was examined with LC-MS/MS, which is shown in the left panel of Fig. 2. Due to the complex components of cell lysate, the experiment was performed with a 5500 Q-TRAP triple quadru- pole, tandem mass spectrometer coupled with an Electrospray Ionizer. 4-amino-SAHA was added in the H292 cancer lysate and incubated at $37^{\circ} \mathrm{C}$ for $30 \mathrm{~min}$. After protein precipitation with acetonitrile, the sample was directly used for the experiment to develop a method for the detection of the compound (upper panel of Fig. 2). Consequently, the conjugate was incubated with the same fresh cell lysate for $30 \mathrm{~min}$, and the generated 4-amino-SAHA was detected with the same method to check if the conjugate could be hydrolyzed by the enzymes in the cell lysate (low panel of Fig. 2). The signal was weak due to the low amount of 4-aminoSAHA from the hydrolyzed conjugate. There are three possibilities for the low amount of generated 4-amino-SAHA. First, the lysing process may damage the digestive enzymes in the lysosomes and the enzyme catalytic capability is harmed. Second, the carbamate group between the cholesterol and 4-amino-SAHA cannot be recognized by the digestive enzyme very well. Third, the carbamate<smiles>COC(=O)CCCCCC(=O)O</smiles>

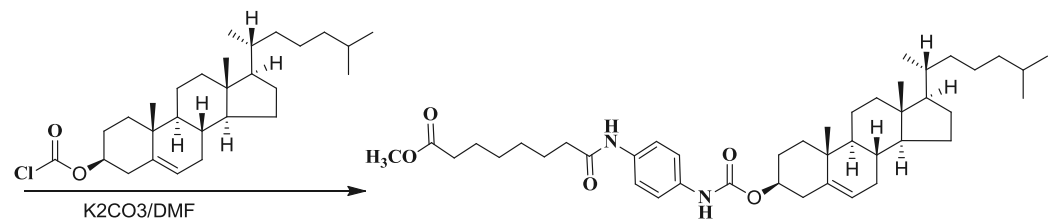

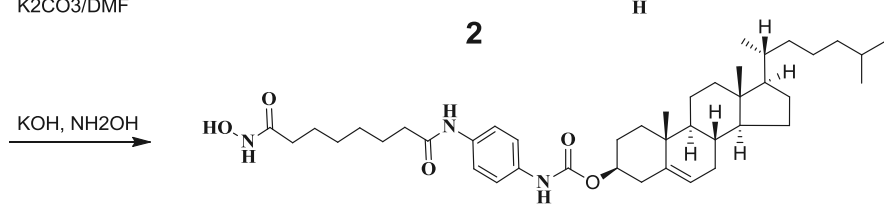

3

Scheme 1. Synthesis of the cholesterol conjugated SAHA.
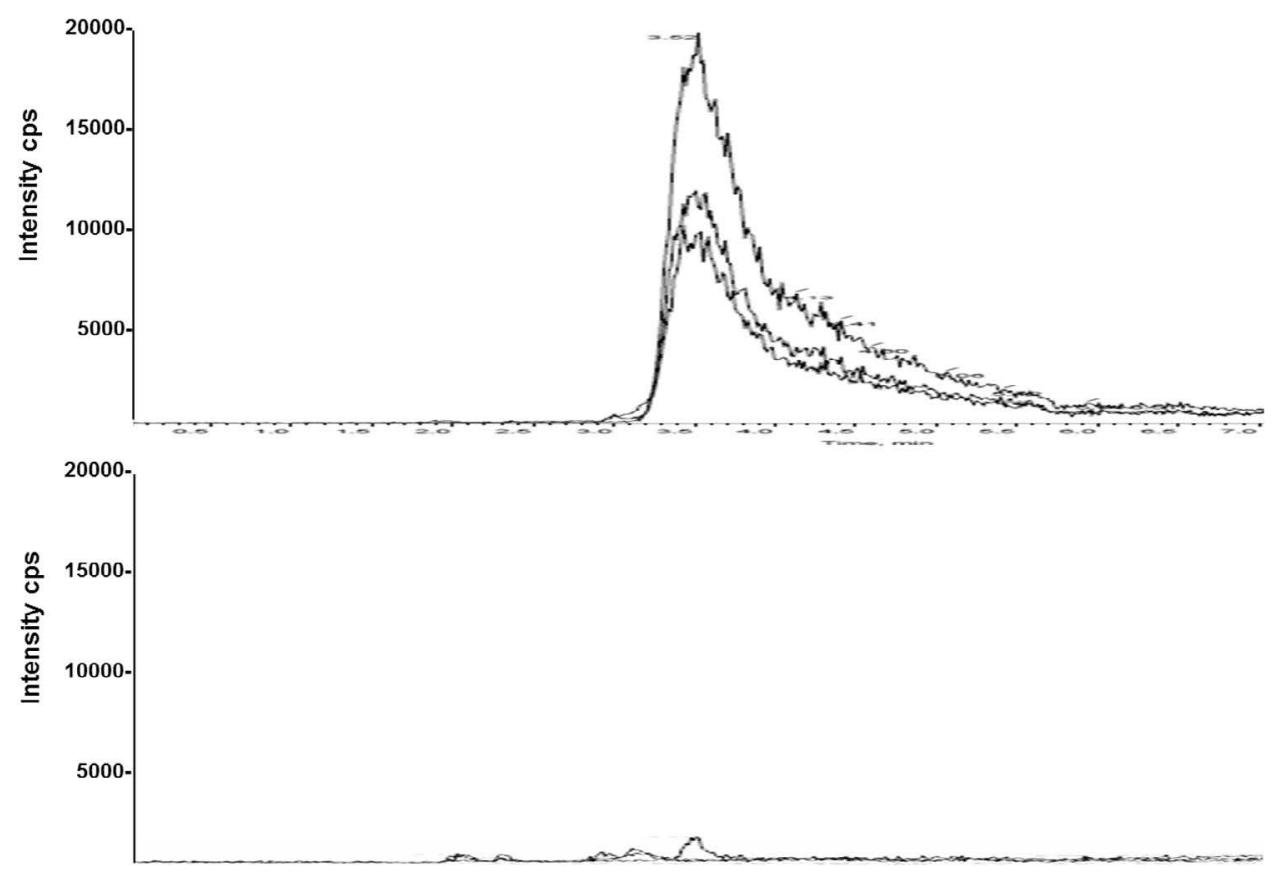

Fig. 2. Hydrolysis of the conjugate by the cancer cell lysate. The conjugate was incubated with $\mathrm{H} 292$ cancer cell lysate at $37^{\circ} \mathrm{C}$ for $30 \mathrm{mins}$. After protein precipitation, the generated 4-amino-SAHA was determined with LC-MS/MS(5500 Q-TRAP triple quadrupole, tandem mass spectrometer (AB Sciex, Toronto, Canada)coupled with an Electrospray Ionizer (Framingham, Massachusetts, USA) and interfaced with High Performance Liquid Chromatography). 
group is much more stable than the ester bond and cannot be effectively hydrolyzed by the enzymes. Nevertheless, the results demonstrate that the conjugate could be hydrolyzed by the digestive enzymes in the cytosol, although the efficiency needs some improvement in the future. The conjugate is still a good tool for us to test our hypothesis of the 4-amino-SAHA delivery.

Consequently, the conjugate was loaded into LDL particles via sonication. Commercially available LDL shows a diameter about $48 \mathrm{~nm}$ (Fig. 3). After sonication, the broken LDL particles were reformed into new particles overnight, and the new particle size was much bigger than the original particles and reached a diameter about $164 \mathrm{~nm}$. When the conjugate was introduced during the sonicating and re-forming process, the newly formed particle size was similar to the vehicle control group with a diameter of $171 \mathrm{~nm}$. The direct evidence of the conjugate loaded into the particles is the aqueous solubility of the conjugate. Before loading into the LDL particles, the conjugate significantly precipitated in aqueous solution at $20 \mu \mathrm{M}$. However, the conjugate loaded into LDL did not show any precipitation even at $500 \mu \mathrm{M}$ in aqueous solution. When the conjugate was introduced into the LDL solution without sonication, the size of the particles was also dramatically increased to $193 \mathrm{~nm}$, which was actually due to the precipitation of the conjugate in aqueous solution. The precipitated conjugate interacted with the LDL and formed large aggregated particles.
To check the biological activity of the compounds and the LDL particles containing the conjugate, these compounds were tested with H292 lung cancer cell proliferation assay. First, the inhibitory effect of these compounds to the growth of cancer cells without LDL as the delivery vehicle was determined. The results exhibited that SAHA and amino-SAHA inhibited cancer cell growth with similar $\mathrm{IC}_{50} \mathrm{~S}$ at sub micromolar levels, which is consistent with the other study. ${ }^{11}$ The conjugate did not show any inhibition to the cell growth, and it significantly precipitated in the cell culture medium during the treatment even at $20 \mu \mathrm{M}$ (Fig. 4). The results suggest that the conjugate cannot get into the cells directly without LDL as the vehicle.

Next, the cells were treated with the compounds plus LDL without sonication, and the control was DMSO and same amount of LDL in the treatment. It should be noted that SAHA and aminoSAHA showed similar activity in inhibiting cancer cell growth, which is consistent to the treatment without LDL (Fig. 5). The results suggest that the LDL did not affect the activity of the SAHA and amino-SAHA. The conjugate still significantly precipitated in the cell culture medium even at $20 \mu \mathrm{M}$ and did not show inhibitory effect to the cell growth, which was actually expected. This was because the conjugate was just mixed together with the LDL without sonication and it was not loaded into the LDL particles.

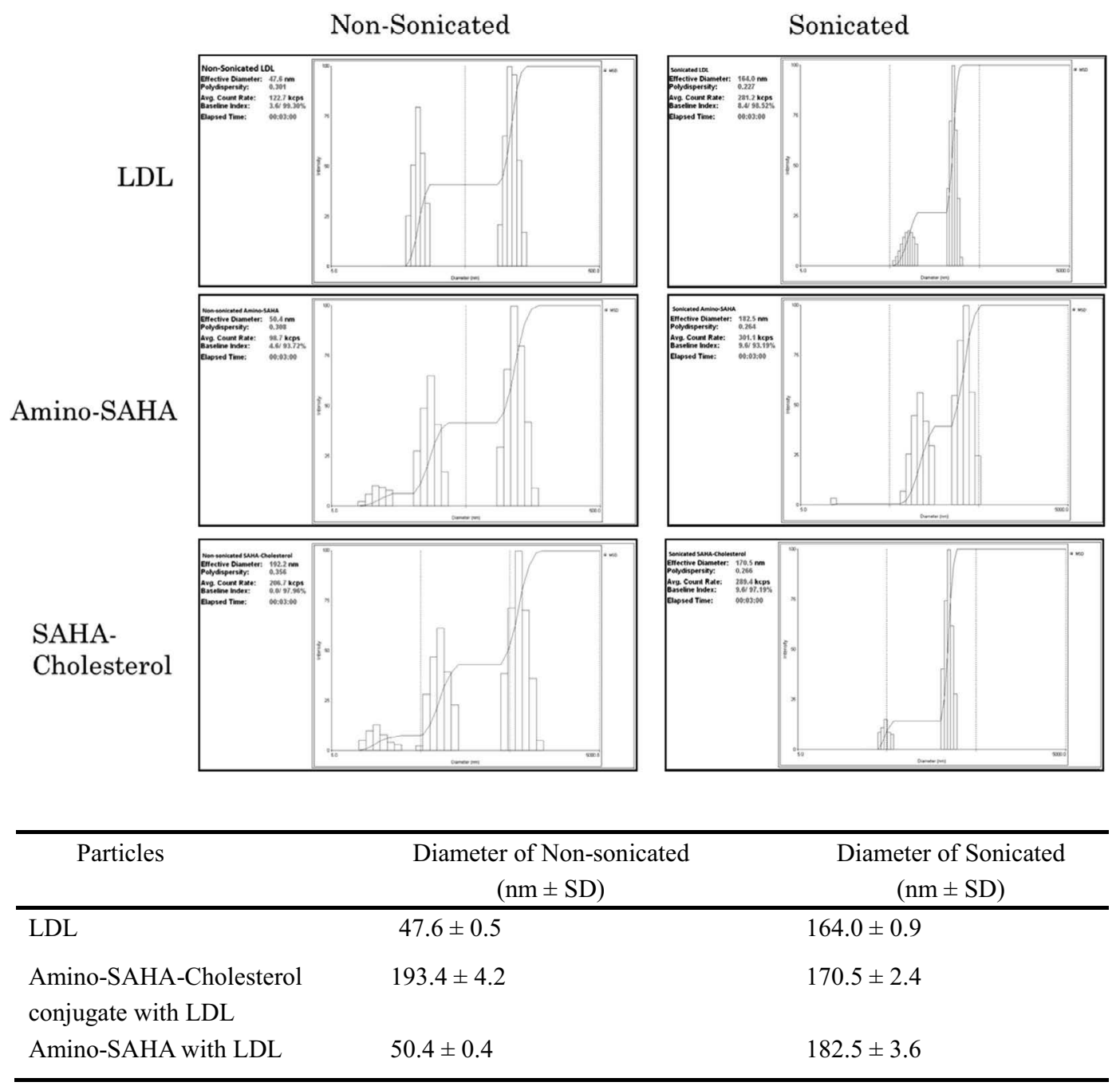

Fig. 3. LDL particle size was determined in PBS by dynamic light scattering (DLS). 


\begin{tabular}{ll}
\hline Treatment & $\begin{array}{l}\text { IC50 values } \\
(\mu \mathrm{M} \pm \mathrm{SD})\end{array}$ \\
\hline SAHA & $1.11 \pm 0.85$ \\
$\begin{array}{l}\text { Amino-SAHA-Cholesterol } \\
\text { conjugate }\end{array}$ & $>500$ \\
Amino-SAHA & $2.77 \pm 1.26$ \\
\hline
\end{tabular}

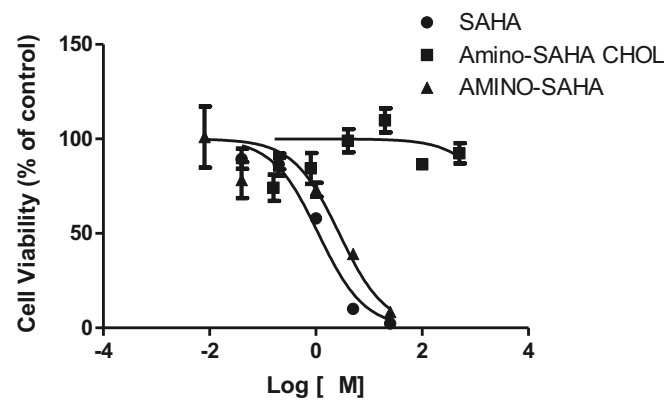

Fig. 4. Growth inhibitory effects of the compounds on H292 cells. The cells were treated with DMSO or the compounds for 72 h. Cell viability was measured by MTT assay. The treatments were quadruplicated and repeated three times.

\begin{tabular}{ll}
\hline Treatment & $\begin{array}{l}\text { IC50 values } \\
(\mu \mathrm{M} \pm \mathrm{SD})\end{array}$ \\
\hline SAHA + LDL & $5.15 \pm 3.58$ \\
$\begin{array}{l}\text { Amino-SAHA-Cholesterol } \\
\text { conjugator + LDL }\end{array}$ & $>500$ \\
Amino-SAHA + LDL & $14.94 \pm 10.85$ \\
\hline
\end{tabular}

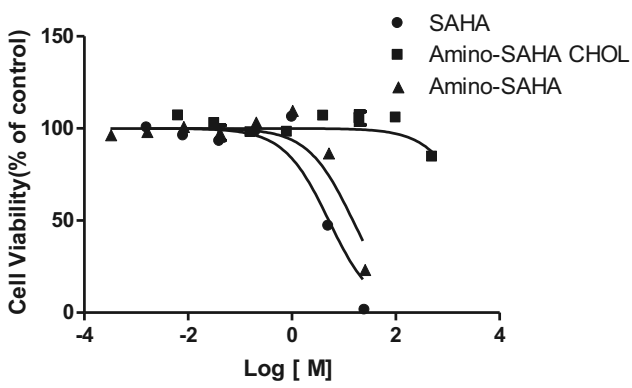

Fig. 5. Growth inhibitory effects of the compounds mixed with LDL on H292 cells. H292 cells were treated with DMSO plus LDL and the compounds for 72 h. Cell viability was measured by MTT assay. The treatments were quadruplicated and repeated three times.

Subsequently, the cells were treated with LDL combination with the compounds after sonication. The reformed particles were much bigger than the original LDL particles as exhibited in Fig. 3. The control was DMSO plus LDL after sonicating and re-forming. SAHA and amino-SAHA also showed similar activity in inhibiting cancer cell growth. The results suggest that SAHA and amino-SAHA can effectively penetrate into the cells and inhibit cell growth regardless of the LDL (Fig. 6). Due to their good solubility, these compounds are less likely to be loaded into the LDL particles via simple sonicating process. So they mainly enter the cells in free drug form via passive diffusion to show their activity. The conjugate did not precipitate in the cell culture medium even at $500 \mu \mathrm{M}$, suggesting that the conjugate was loaded into the particles. To our surprise, the conjugate did not show inhibitory effect to the cell growth (Fig. 6).

We speculate that the low activity of the conjugate may be due to the low cellular uptake of the new LDL particles. Regular fetal bovine serum (FBS) that is rich in LDL was used for the assay, and the LDL particles may compete with our conjugate loaded LDL particles for LDL receptor. To confirm the hypothesis, LDL depleted FBS was used to repeat the last experiment and the results are listed in Fig. 7.

SAHA and amino-SAHA inhibited the cell growth with $\mathrm{IC}_{50} \mathrm{~S}$ at sub micromolar concentrations, which are similar to the results in Fig. 6. The conjugate showed significantly improved activity to inhibit cell growth with an $\mathrm{IC}_{50}$ of $91.22 \mu \mathrm{M}$ compared to the results in Fig. 6 . The results indicate that the cells did recognize the reformed LDL particles, and the conjugate was delivered into cells and inhibited cell growth. However, the activity of the conjugate was not as high as the amino-SAHA, suggesting that the delivery efficacy was not good enough to be comparable to the passive penetration of free amino-SAHA. This could be due to the low hydrolysis efficiency of the carbamate group as well. Nevertheless, if the cancer cell uptake and conjugate hydrolysis can be improved, this conjugation is a feasible strategy to enhance the selective delivery of chemotherapeutical agents into cancer tissue.

In summary, our findings indicate that cholesterol conjugated SAHA could be up-taken by cancer cells via LDL receptor after loading into LDL particles. Due to the increased LDL receptor in cancer cell surface, this strategy has the potential to increase the selectiv-

\begin{tabular}{ll}
\hline $\begin{array}{l}\text { Treatment (LDL + compound } \\
\text { was sonicated and re-formed) }\end{array}$ & $\begin{array}{l}\text { IC50 values } \\
(\mu \mathrm{M} \pm \mathrm{SD})\end{array}$ \\
\hline SAHA + LDL & $4.61 \pm 2.98$ \\
$\begin{array}{l}\text { Amino-SAHA-Cholesterol } \\
\text { conjugate + LDL }\end{array}$ & $>500$ \\
Amino-SAHA + LDL & $14.65 \pm 8.90$ \\
\hline
\end{tabular}

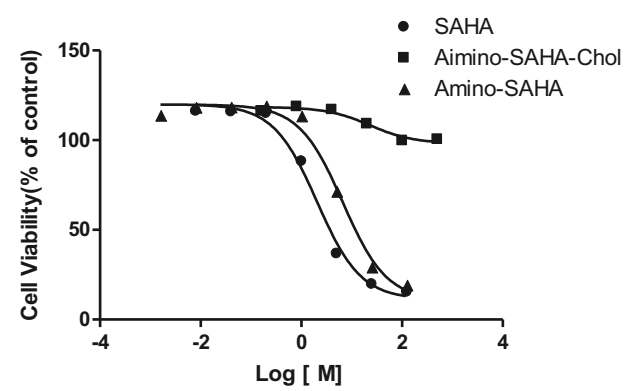

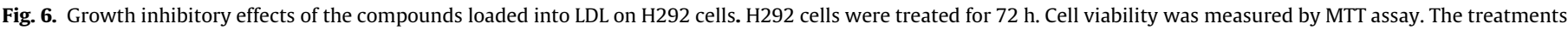
were quadruplicated and repeated three times. 


\begin{tabular}{ll}
\hline $\begin{array}{l}\text { Treatment (LDL + compound } \\
\text { was sonicated and re-formed })\end{array}$ & $\begin{array}{l}\text { IC50 values } \\
(\mu \mathrm{M} \pm \mathrm{SD})\end{array}$ \\
with LDL depleted FBS & \\
\hline SAHA + LDL & $2.01 \pm 0.65$ \\
Amino-SAHA-Cholesterol & $91.22 \pm 33.12$ \\
conjugate + LDL & \\
Amino-SAHA + LDL & $7.80 \pm 2.81$ \\
\hline
\end{tabular}

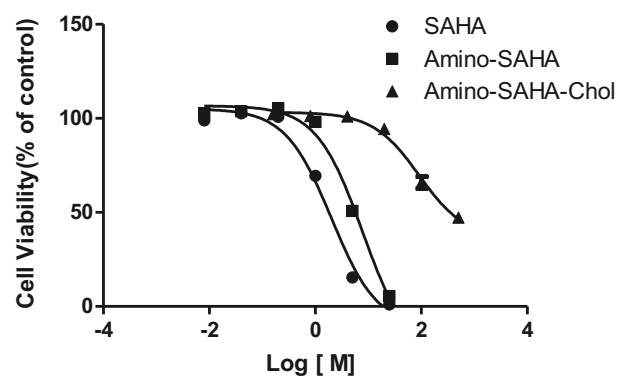

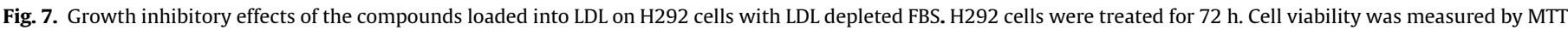
assay. The treatments were quadruplicated and repeated three times.

ity of a chemotherapeutical agent to cancer tissue than normal tissue that has relatively lower LDL receptor. Further research into other chemo agents conjugated with cholesterol and the loading efficacy of the conjugate into LDL with a more quantitative method are still undergoing.

\section{Acknowledgments}

This work was supported by Center for Gene Regulation in Health and Disease (GRHD) of Cleveland State University and Ohio Department of Development (ODOD) and Cleveland State University summer undergraduate research program.

\section{References}

1. He L, Lu Y, Wang P, Zhang J, Yin C, Qu S. BMC Cancer. 2010;10:601.

2. Liu J, Xu A, Lam KS, et al. Oncotarget. 2013;4:1804.

3. Vitols S, Peterson C, Larsson O, Holm P, Aberg B. Cancer Res. 1992;52:6244.

4. Goldstein JL, Brown MS. Arterioscler Thromb Vasc Biol. 2009;29:431.

5. Sengupta P, Basu S, Soni S, et al. Proc Natl Acad Sci USA. 2012;109:11294.

6. Huntosova V, Buzova D, Petrovajova D, et al. Int I Pharm. 2012;436:463.

7. Slingerland M, Guchelaar HJ, Gelderblom H. Anticancer Drugs. 2014;25:140.

8. Muscat A, Popovski D, Jayasekara WS, et al. Clin Cancer Res. 2016;14:3560.

9. Shen L, Orillion A, Pili R. Epigenomics. 2016;8:415.

10. Duvic M, Dimopoulos M. Cancer Treat Rev. 2016;43:58.

11. Salmi-Smail C, Fabre A, Dequiedt F, et al. J Med Chem. 2010;53:3038.

12. Vacondio F, Silva C, Lodola A, et al. Chem Med Chem. 2009;9:1495. 